\title{
Dissemination of Direct Instruction: Ponder These while Pursuing That
}

\author{
Patrick C. Friman ${ }^{1}$ (D) \\ Accepted: 25 February 2021/ Published online: 2 August 2021 \\ (C) Association for Behavior Analysis International 2021
}

\begin{abstract}
We happy few but why so few is a question initially posed by Skinner and subsequently posed by many members of the behavior-analytic community, and advocates for Direct Instruction (DI) are no exception. On the contrary, the limited extent to which DI has been adopted by the educational community is an abiding source of frustration for DI devotees. This article contains little information about DI, which parallels the amount its author has to share. Instead the article focuses on five concepts, attention to which could improve disseminative efforts for behavior analysis in general and DI in particular. The five concepts are social validity, marketing, being behavior analytic, the behavioral dynamics of training, and politics. Failure to address any or all of these could supply at least a partial answer to the question posed by Skinner and subsequently by like-minded behavior analysts and DI advocates.
\end{abstract}

Keywords behavior analysis $\cdot$ direct instruction $\cdot$ social validity $\cdot$ dissemination

While preparing for my role as discussant on the symposium that led to this special section (Heward, 2020), I learned that Direct Instruction (DI) is one of the most effective methods ever invented for educating children (Stockard et al., 2018). This led to a few questions, such as: why is it not popular, or why hasn't the entire educational community adopted it? Putting those questions into behavior-analytic terms, what is the function underlying the use of alternative ways to teach? I cannot answer that question, although I will speculate below. Here I will just assert that for behavior analysts that question should be, if not the only one asked about those who eschew DI, the primary one.

I confess that prior to my invitation to be discussant I had not heard of DI. This is not quite as negligent as it sounds. I am a clinical psychologist and thus I am largely

Patrick C. Friman

Patrick.friman@boystown.org

1 Center for Behavioral Health, Boys Town and the University of Nebraska School of Medicine, 13460 Walsh Drive, Boys Town, NE 68010, USA 
ignorant of the educational literature in all its dimensions, including DI. It may be presumed that my confession will result in some questions about why I am even involved in this project. Or back to the symposium, why would the chair ask a patently uninformed person to synthesize four papers on DI and distill from them a thematically larger unifying message, in other words, to be discussant? I surmise that I was chosen because my practice is to put forth a generic behavior-analytic perspective on any subject about which I am asked to speak. This perspective is composed of two functions of behavioral analysis that are integral to the field yet not always demonstrably apparent in its manifestations: (1) disseminating the circumstances view of behavior; and (2) making the world a better place. Employing these two functions as a place to stand enables me to have something relevant to say about any aspect of behavior analysis including DI. I will return to my generalist perspective in my concluding remarks. Here I will address five concepts attention to which could increase the dissemination of DI in particular, and behavior analysis in general: social validity, marketing, being behavior analytic, the behavioral dynamics of training, and politics.

\section{Social Validity}

In a manner not unlike Newton's and Leibniz's nearly simultaneous description of the calculus (Arthur, 2008), Wolf (1978) and Kazdin (1977) simultaneously described social validity. Serendipity of this sort in science reflects the appearance of innovations that satisfy unmet but critically important technical needs and thus stimulates scientific growth. It is not unusual for stakeholders in a science to be concurrently but independently working on the same problem. Both Wolf and Kazdin recognized something was missing in applied behavior analysis. Kazdin thought it was concern for the consumer. Wolf endorsed that view and went even further, in a metaphorical sense, and called it heart. Whether what followed satisfied either man's expectation is impossible to know although I take a pessimistic view. True, after those articles, applied behavior-analytic researchers began to add a social validity section to their submissions, especially if the target was the Journal of Applied Behavior Analysis $(J A B A)$. This represented progress but only for a small dimension of behavior analysis, one that included investigators attempting to have their articles published in JABA. For real progress, however, social validity efforts would have to focus on behavior analysis itself as well as all the interventions it inspires such as DI.

The three dimensions of social validity are the target, intervention, and outcome, and they are equally important; failure to establish consumer acceptance of any one of them is likely to diminish acceptance of a program. For example, if therapist and client agreed on the target and the intervention but were highly disparate on the outcome, by whose judgement is success to be determined: the client's or the therapist's?

Thus, social invalidity of DI in any of the three dimensions could account for the limited acceptance of DI in the educational community at large. Attempting to introduce DI into an educational setting is not unlike prescribing a treatment to a client. First, the therapist and the client must agree that there is a problem and on what that problem is. It is clear that proponents of DI and probably most behavior-analytic members of the educational community agree that there is a problem with education today, broadly defined. The title of Skinner's (2017) article, "The Shame of American 
Education," is representative of the behavior-analytic view. The title of Engelmann and Carnine's (2011) book, Could John Stuart Mill have Saved Our Schools, is representative of the DI and behavior analytic view. But do nonbehavior-analytic members of the educational community share or accept that view? If not, herein lies a big problem. If the members of a therapeutic relationship disagreed on the existence and nature of the referral problem, the clinical endeavor would likely not get past the initial encounter. Turning to the intervention, the educational community clearly does not share the affectionate behavior-analytic view of DI. Why is not important here but in the presence of failed disseminative efforts knowing why is critical. Such knowledge could inform new efforts. Finally, the Achilles heel of virtually all attempts to disseminate behavioranalytic interventions: outcomes. It seems as if the behavioral community has placed all its persuasive capital on outcomes. That DI produces better outcomes on a select portion of educational targets is not in dispute (Stockard et al., 2018). Although consistent with the theme of this article, reasonable questions include who did the selecting and what is the social validity of the targets. Assuming that superior outcomes on these targets are enough to persuade the educational community to adopt DI, however, reflects some naiveté about human decision making. In other words, outcomes are merely part of the decision dynamics that influence consumption. Diet and exercise produce significantly better outcomes than dietary indulgence and motoric inactivity on a range of health indices such as obesity and diabetes type II. Yet both conditions are at alarmingly high and rising levels (Jensen, 2020; Nathan, 2015). The community at large apparently does not share the affectionate view the health-care community has of diet and exercise.

Multiple variables other than outcomes influence whether persons will adopt behavior change programs. For example, a recent study shows that parents of children receiving behavioral treatment will discount the value of the effectiveness of those services if they do not feel valued by the provider (e.g., Chadwell et al., 2018). A pertinent question is whether nonbehavior-analytic members of the educational community feel valued by the behavior-analytic members of that community - in particular because those members attempt to persuade the nonbehavior-analytic members to adopt DI. The relationship between provider and client has been shown to play a significant role in the adoption of, and outcome from, prescribed treatment and that role is largely independent of the empirical status of the treatment (e.g., Allen \& Warzak, 2000; Friman, 2015; Lambert, 2013; Norcross \& Wampold, 2011; Patterson \& Forgatch, 1985). Prudence dictates that the relationship between the purveyors of DI and potential consumers should receive some scrutiny.

In other words, Engelmann created a better mousetrap, so to speak (Engelmann \& Carnine, 1982) but its effectiveness is also only a portion of the means necessary to persuade consumers to use it. The obsolescent merchandise repository is full of products that are operationally superior to still popular products that serve the same purpose but less effectively. For example, the Dvorak keyboard is arguably faster, easier, and less prone to cause chronic use ailments (e.g., carpal tunnel syndrome) than the Qwerty keyboard. Good luck finding one. Pepsi routinely beats Coca Cola in taste tests, but Coca Cola dominates Pepsi in sales worldwide. In addition, medical providers recommend a variety of effectively protective interventions that are widely ignored. For example, vaccines reliably protect hosts from infection and yet there is a large antivaccination movement. Facemasks reliably prevent hosts infected by COVID-19 
from infecting others and yet there is a large anti-mask movement. There are numerous other examples. The point is that having an effective product, even one that is demonstrably superior to other products that serve the same or similar purposes, is not enough for establishing its widespread consumption.

Consistent with this point in particular, and social validity in general, is a perspective from outside the behavior analytic and educational communities, in particular diffusion of innovations. The eponymously titled book by Rogers (2019) is now in its sixth edition, and has been cited more than 100,000 times, vastly more than any behavioranalytic document ever published. It describes diffusion (synonymous with dissemination) as a social process more than a technical one, specifying that an innovation should (1) solve a problem for potential consumers; (2) have an advantage over existing practices; (3) be consistent with the values, beliefs, and experiences of potential consumers; and (4) its principle advocate must have high credibility with the intended consumers. It does not take much consideration to see that DI may not sufficiently meet all of these criteria, which could partially explain why DI is not widely adopted in the educational community.

\section{Marketing}

From a slightly different perspective, behavior analysis has a marketing problem (e.g., Friman, 2010a, 2010b, 2017). On the one hand, it can be argued that its foundational ideological predicate (that behavior is a function of circumstances) is the most powerful idea ever articulated for understanding, knowing, and approaching human behavior, especially when it is a problem. Applications derived from this idea are astonishing in their power and scope. Behavior-analytic-informed interventions have been successfully applied to an incredibly diverse array of human problems ranging from prototypical aberrant behaviors accompanying a variety of disability syndromes to male infertility. In fact, they have brought the possibility of behavioral normalcy to persons afflicted with syndromes historically thought to be beyond clinical improvement, such as autism and Tourette's syndrome. On the other hand, behavior analysis does not seem to be getting much traction insofar as relevance to the mainstream of the human population is concerned. It flourishes in one tail of the normal distribution and flounders when it comes out from under it.

The explanation for this is not bad marketing, because implicit in that proposition is that marketing has been attempted. I submit that behavior analysts have never been serious about marketing. Why this is so is due, at least in part, to an apparent arrogant provincialism that is appropriate in some contexts but never in a marketing context. Supportive examples are plentiful but a sample from Skinner, starting with "The Shame of American Education" (Skinner, 2017) mentioned above, should suffice. In politics, provocations like this are known as "appealing to your base." But although they excite the base, they irritate virtually everyone else. Another example of appealing to the base is Skinner's 1983 article, "Can the Experimental Analysis of Behavior Rescue Psychology?" As appeals to the base, these articles were laudable; as attempts to market behavior-analytic approaches to the nonbehavior-analytic educational and psychological communities they were lamentable. At the time of their publication, the base represented only a tiny fraction of the educational and psychological communities. In 
response to concerns about perceived provincialism, Skinner doubled down: "We have been accused of creating our own ghetto. . . Rather than break out of the ghetto I think we should strengthen its walls" (Skinner, 1993, p. 5). Subsequent suggestions that provincialism might pose problems for dissemination of behavior analysis (e.g., Critchfield \& Farmer-Dougan, 2015) have been met with peremptory rebuttal within behavior analysis (e.g., Ullman 2015).

Skinner also expressed provincialism within behavior analysis itself, most notably by referring to interbehaviorists as cuckoos, birds known to use the nests of other birds to lay their eggs (Skinner, 1988). His article was harshly critical of interbehaviorists and it did not disguise his wish to have them leave behavior analysis. As indicated, behavior analysis was a tiny community then and the intent of Skinner's article was to reduce its size, despite the ideological similarity between behavior analysis and interbehaviorism. In other words, he appeared to be more concerned with ideological purity than with expanding the consumer base of behavior analysis (otherwise known as marketing). In fairness, expecting the inventor of a product to also market that product is probably expecting too much. But there are very few actual examples of behavior analysts who have actively marketed behavior analytic perspectives outside the field. Those that have, however, are often successful.

For example, Christophersen successfully persuaded pediatricians to embrace behavior-analytic approaches to child misbehavior. He did this not by arguing that nonbehavior-analytic approaches were inferior, but by using the logistics and language of pediatric practice to tout the advantages of behavior analysis for pediatric primary care (Christophersen, 1982). His marketing scheme emphasized five aspects of primary care: (1) prevention is the overarching goal; (2) up to $50 \%$ of all primary care pediatric visits involve behavior problems - typically lowintensity/high-frequency problems that respond well to direct contingencies; (3) pediatricians do not have the time, training, nor even the inclination to spend large portions of clinic time trying to solve behavior problems; (4) pediatricians favor short-term, efficient, empirically supported interventions; (5) pediatricians place high value on communications from providers to whom they have referred their patients. He did not bemoan the relative absence of behavioral applications in pediatric practices. He criticized neither the pediatricians for referring patients to nonbehavioral providers nor those providers for using treatments that were demonstrably inferior to behavioral methods. Instead, he conducted research showing various ways behavior analysis could benefit pediatrics and published them in pediatric medical journals (e.g., Christophersen, 1982, 1985; Christophersen et al., 1986). His articles advertised, and the training of his students emphasized, that attention to the five aspects of pediatric practice listed above was fundamental to the integration of behavior analysis and pediatric primary care. That he was successful is beyond dispute. There are behavioral pediatric clinics across the United States, at least five of which are in Nebraska. Behavior analysts have edited three issues of the prestigious Pediatric Clinics of North America that focused on behavioral pediatric themes (Christophersen, 1982; Christophersen et al., 1986; Roane, 2020). The general message is that behavioral pediatrics is marketed as a benefit to pediatrics, not a corrective. It is an enhancement of success, not the satisfaction of a deficiency (Friman, 2021a, b). 


\section{Be Behavior Analytic}

There are two main models for understanding human behavior, internal and external. The internal model attributes behavior to something internal to the person (e.g., character, personality, morality, the psyche). The external model attributes behavior to something external to the person, i.e., circumstances, and thus the person is seen as the locus of behavior, not the cause. The external model is the foundation for behavior analysis. To be behavior analytic is to embody the external model in human affairs. Although there are thousands of persons who identify themselves as behavior analysts, it is highly unlikely that any of them embody the external model in all, or even very many, of their interactions with other persons. It is challenging to fully comprehend how radically counterintuitive that would be. For example, disappointment in, or anger at, someone because they did or did not do something important would be entirely misdirected. Just as it would if someone was angry at a stove because their fingers were burned when they touched it. The stove burned their fingers, but it did not cause itself to be touched or hot. In kind, it would not make sense to criticize persons who favor nonbehavioral interventions (e.g., whole language) despite abundant evidence showing that behavioral interventions (e.g., DI) produce superior outcomes. From an educational perspective, they have made the wrong choice, but they did not make themselves choose it. To be behavior analytic would mean focusing on what circumstances are functionally related to the choice. It would also involve attempting to fix the problem, not the blame. As Skinner said to his young graduate student, Ogden Lindsley, "the rat is always right" (Vargas, 2020, p. 160) or to his colleague, Sidney Bijou, "the animal is always right" (Bijou, 1999, p. 183). A related Precision Teaching slogan is "the child knows best" (Lindsley, 1991). A similar saying in the business community is that the customer is always right, although for the present theme, the word "consumer" is preferable.

One group of potential consumers includes members of the educational community who choose educational methods other than DI. From a behavior analytic point of view there is nothing wrong with this choice; it occurs as a function of historical stimulus conditions. In other words, the consumer is always right. Being behavior analytic would include embodying that perspective, identifying (as much as possible) the stimulus conditions responsible for the choice, and rearranging conditions to make choice of DI more likely.

Members of the business community who market or advertise (marketers hereafter) provide an instructive example. It is ironic that they are frequently more behavior analytic (consistent with the usage of the term here) than behavior analysts themselves, despite being entirely ignorant of behavior analysis. Distilled to its essence, their occupation involves arranging stimulus conditions that establish preferences and lead to purchases. It seems safe to say that they have no attachment to the products they market, at least not to the same extent that DI devotees have for DI. Nonetheless, the marketers' methods are routinely effective. For example, they arrange stimulus conditions that result in purchase of products (e.g., bottled water) that are otherwise available for free (e.g., tap water), higher payment for inferior products (e.g., ripped clothes) that are available for lower payment in a superior form (e.g., unripped clothes), or purchase and consumption of products that are notoriously unhealthy (e.g., tobacco, alcohol). If a stimulus arrangement does not produce preference and purchase, they do not assume there is something wrong with the potential consumer, they assume there is something wrong with the arrangement and so they rearrange conditions and try again. This is an 
example of being behavior analytic; in particular, it is the ontological stance that the source of behavior is in circumstances, not the person.

\section{The Behavioral Dynamics of Training}

Another potential obstacle involves how challenging it is to train persons to develop and use a new skill set. It is difficult even when they have asked and agreed to be trained, close to impossible if they have not. Training a new skill requires moving trainees out of a context of what they know well into one where they know little or nothing at all. To express this colloquially it involves moving trainees from a context where they can easily look good and be right into one where they could look bad and be wrong. To express it behavior analytically it involves moving trainees from a context where their behavior routinely contacts reinforcement into one where it will likely contact punishment. It is not surprising that attempts to train are frequently met with resistance, even when people sign up to be trained. When this happens, it would be helpful to recall Skinner's position that the trainee (whether it be human or infrahuman) is always right. It is thus incumbent upon the trainer to revise the program, just as marketers do when they encounter resistance to their programs.

How plausible this is for purveyors of DI is not clear. Once again, I profess my ignorance of DI. I presume that the typical approach is top down, meaning proponents attempt to persuade school administrators to implement DI in schools or even school systems. Success in the executive office, however, does not guarantee compliance in the classroom.

\section{Politics}

At its simplest level, politics involves people making agreements so they can live and work together in groups (e.g., school systems, cities, states). Resistance to innovation is often due to preexisting agreements that would be diminished or undone if the innovation were to be implemented. These agreements established contingencies that have maintained the status quo. Proponents of an innovation (e.g., DI) should determine in advance who will be affected by its implementation and how. There are likely to be persons who are adversely affected. Failure to identify them in advance and to take steps to ameliorate the adversity is an establishing operation for resistance.

Another potential pitfall involves over-reliance on data. I realize this might sound like heresy to the readership of the Journal and the devotees of DI but it really is not. I'm not discounting the value of data just pointing out that relying on data alone to persuade others often cedes the persuasion to those who use more powerful tools. There is now, and quite possibly always has been, widespread bewilderment over fiercely held political positions that are patently inconsistent with available facts. The bewildered are gobsmacked by the apparent irrationality of those positions. The presuppositions underlying the reactions are that irrational positions are invalid or are not to be taken seriously. The bad news for the rationally minded is that a substantive portion of human decision making is done more on emotional than rational basis (e.g., Sharot, 2017). For example, during the 2016 presidential debates Dr. Ben Carson alluded to the 
large body of research refuting the belief that vaccination causes autism. Donald Trump responded by describing one small child stabbed with one giant needle who then became autistic. Whether the child in question actually existed or was merely a rhetorical invention is impossible to know. But in terms of the relative persuasion of each man's position, point, set and match to Trump (Sharot, 2017). More currently, despite extensive investigation and litigation showing no significant fraud in the 2020 presidential election, a large segment of United States citizens believe its results were fraudulent. In short, and with regrets to behavior analysts and DI devotees, databased evidence is all too often insufficient to change beliefs. On a more optimistic note, it is possible to change beliefs (and practices) by telling emotionally impactful stories that include data (e.g., Friman, in press; Maurice, 1993). Although, as indicated, I know virtually nothing about the educational literature, DI and otherwise, it does seem possible that adherents of instructional methods that are indirect tell more emotionally resonant (persuasive) stories than DI adherents. This is not necessarily bad news. DI adherents could merely match to their sample. After all, they have the data. I presume an emotionally resonant story that also has good data would be more persuasive than the emotionally resonant story alone.

\section{Conclusion}

In closing I return to my generic perspective. Behavior analysts all serve two functions, disseminating the foundational idea underlying behavior analysis and making the world a better place. Serving these functions does not require awareness of them nor does it matter what professional position one holds. The field serves those two functions and ipso facto if one is in the field, he or she also serves the functions. However, I assert that as one becomes aware of the functions and purposely serves them, their behavior analytic work becomes more automatically reinforcing and less dependent upon contingent positive reinforcement. In colloquial terms they will begin doing their work because they love doing it. Some behavior analytic activities might challenge one's capacity to see the two functions, but DI is not one of those. On the contrary, it obviously embodies the circumstances view of behavior and its mission is to transform the quality of education, not just for some children, but all children. It seems selfevident that doing so would indeed make the world a better place. Some purveyors of DI are likely frustrated by its limited acceptance in the educational community. It may help to focus on the two functions and the paradigm shifting intent behind them. The mission is simply to transform the quality of the way human beings think about and interact with each other. Those pursuing the mission are up against ways of thinking and interacting that are buttressed by thousands of years of cultural instantiation and billions of adherents. Expecting widespread adoption of any behavior-analytic innovation over the short term is bound to result in disappointment.

It may also help to redefine measures of success for DI, perhaps narrowing them down to one student at a time. Although the goal of Alcoholics Anonymous is complete sobriety, it measures success one day at a time. The field of applied behavior analysis was inaugurated with interventions targeting simple noncompliance (refusal to wear glasses) in one child (Wolf et al., 1964). The number of persons in behavior analysis who do applied work is now nearing 100,000. Martin Luther King famously said, "the moral arc of the universe is long 
and it bends towards justice." Let me paraphrase by saying the arc of the educational universe bends towards child learning and well-being. I assert that methods that optimally contribute to those goals will inexorably be incorporated into educational practices - but, alas, slowly. It took thousands of years to get here. It will likely take more than a few decades to get there. Meanwhile, ponder the following haiku from the poet Issa: "Oh snail. Climb mount Fuji. But slowly, slowly" (Hass, 1995).

Data Availability N/A

Code Availability N/A

\section{Declarations}

Conflicts of Interest/Competing Interests None

Ethics Approval N/A

Consent to Participate N/A

\section{References}

Allen, K. D., \& Warzak, W. J. (2000). The problem of clinical nonadherence in clinical behavior analysis: Effective treatment is not enough. Journal of Applied Behavior Analysis, 33, 373-391.

Arthur, R. (2008). Leery bedfellows: Newton and Leibniz on the status of infinitesimals. In U. Golenbaum \& D. Jessep (Eds.), Infinitesimal differences (pp. 7-30). Walter de Gruyter.

Bijou, S. (1999). Empirical behaviorism. In W. O’Donohue \& R. Kitchner (Eds.), Handbook of behaviorism (pp. 180-190). Academic Press.

Chadwell, M. R., Sikorski, J. D., Roberts, H., \& Allen, K. D. (2018). Process versus content in delivering A behavior analysis services: Does process matter when you have content that works? Behavior Analysis: Research \& Practice, 19, 14-22.

Critchfield, T., \& Farmer-Dougan, V. F. (2015). Isolation from the mainstream: Recipe for an impoverished science. European Journal of Behavior Analysis, 15(1), 32-38.

Christophersen, E. R. (Ed). (1982). Behavioral pediatrics into primary care. Pediatric Clinics of North America, 29(2), .

Christophersen, E. R. (Ed.). (1985). Developmental and behavioral issues in perinatology. Clinics in Perinatology, 12(2), .

Christophersen, E. R., Finney, J. W., \& Friman, P. C. (Eds.). (1986). Prevention in primary care. Pediatric Clinics of North America, 33(3), .

Engelmann, S., \& Carnine, D. (1982). Theory of instruction: Principles and applications. ADI Press.

Engelmann, S., \& Carnine, D. (2011). Could John Stuart Mill have saved our schools? Full Court Press.

Friman, P. C. (2010a). Come on in, the water is fine: Achieving mainstream relevance through integration with primary medical care. The Behavior Analyst, 33, 19-36.

Friman, P. C. (2010b). Presidential address: Steps to take and missteps to avoid on the quest for mainstream relevance. In Paper presented at the $36^{\text {th }}$ annual convention of the Association for Behavior Analysis International, May 31. TX.

Friman, P. C. (2015). My heroes have always been cowboys. Behavior Analysis in Practice, 8, 138-139.

Friman, P. C. (2017). You are in the way. Opening lines of transmission for Skinner's view of behavior. The Behavior Analyst, 40, 173-177.

Friman, P. C. (2021a). Behavioral pediatrics. In W. Fisher, C. Piazza, \& H. S. Roane (Eds.), Handbook of applied behavior analysis (2 ${ }^{\text {nd }}$ ed.; pp. 433-450). Guilford Press. 
Friman, P. C. (2021b). There is no such thing as a bad boy: The circumstances view of problem behavior. Journal of Applied Behavior Analysis.54, 636-653.

Hass, R. (1995). The essential haiku: Versions of Basho, Buson, \& Issa. HarperCollins.

Heward, W. L. (2020). Siegfried Engelmann's Direct Instruction: Faultless communication, measurably superior learning, and the quest for widespread adoption. Symposium presented virtually at the $46^{\text {th }}$ annual convention for the Association for Behavior Analysis International, May 23.

Jensen, M. D. (2020). Obesity. Endocrinology \& Metabolism Clinics of North America, 49.

Kazdin, A. E. (1977). Assessing the clinical or applied importance of behavior change through social validation. Behavior Modification, 1, 427-452.

Lambert, M. J. (Ed.). (2013). The efficacy and effectiveness of psychotherapy. Bergin and Garfield's handbook of psychotherapy and behavior change (6th ed.; pp. 169-218). Wiley.

Lindsley, O. R. (1991). Thank you, Grandpa Fred! Journal of Precision Teaching, 8, 5-11.

Maurice, C. (1993). Let me hear your voice: A family's triumph over autism. Ballantine Books.

Nathan, D. M. (2015). Diabetes: Advances in diagnosis and treatment. Journal of the American Medical Association, 314, 1052-1062.

Norcross, J. C., \& Wampold, B. E. (2011). Evidence-based therapy relationships: Research conclusions and clinical practices. Psychotherapy, 48, 98-102.

Patterson, G. R., \& Forgatch, M. S. (1985). Therapist behavior as a determinant for client noncompliance: A paradox for the behavior modifier. Journal of Consulting \& Clinical Psychology, 53, 846-851.

Roane, H. S. (Ed.) (2020). Pediatric prevention. Pediatric Clinics of North America, 67(3), .

Rogers, E. (2019). The diffusion of innovations ( $6^{\text {th }}$ ed). Lawrence Erlbaum Associates.

Sharot, T. (2017). The influential mind. Little, Brown.

Skinner, B. F. (1983). Can the experimental analysis of behavior rescue psychology? The Behavior Analyst, 6 , 9-17.

Skinner, B. F. (1988). The cuckoos. ABA Newsletter, 11, 9.

Skinner, B. F. (1993). A world of our own. Behaviorology, 1, 3-5.

Skinner, B. F. (2017). The shame of American education. American Psychologist, 39, 947-954.

Stockard, J., Wood, T. W., Coughlin, C., \& Khoury, C. R. (2018). The effectiveness of Direct Instruction curricula: A meta-analysis of a half century of research. Review of Educational Research, 88, 479-507.

Ullman, J. D. (2015). Reply to Thomas S. Critchfield \& Valerie Farmer-Dougan. European Journal of Behavior Analysis, 15, 39-40.

Vargas, J. S. (2020). Behavior analysis for effective teaching (3rd ed.). Routledge.

Wolf, M. M. (1978). Social validity: The case for subjective measurement or how applied behavior analysis is finding its heart. Journal of Applied Behavior Analysis, 11, 203-214.

Wolf, M. M., Risley, T. R., \& Mees, H. L. (1964). Application of operant conditioning procedures to improve the behavior problems of an autistic child. Behavior Research \& Therapy, 1, 305-312.

Publisher's Note Springer Nature remains neutral with regard to jurisdictional claims in published maps and institutional affiliations. 